\title{
Initiation factor-independent translation mediated by the hepatitis $C$ virus internal ribosome entry site
}

\author{
ALISSA M. LANCASTER, ERIC JAN, and PETER SARNOW \\ Department of Microbiology and Immunology, Stanford University School of Medicine, Stanford, California 94305, USA
}

\begin{abstract}
The hepatitis C viral mRNA initiates translation using an internal ribosome entry site (IRES) located in the 5' noncoding region of the viral genome. At physiological magnesium ion concentrations, the HCV IRES forms a binary complex with the 40S ribosomal subunit, recruits initiation factor eIF3 and the ternary eIF2/GTP/Met-tRNA ${ }_{i}{ }^{\text {Met }}$ complex, and joins $60 \mathrm{~S}$ subunits to assemble translation-competent $80 \mathrm{~S}$ ribosomes. Here we show that in the presence of $5 \mathrm{mM} \mathrm{MgCl}$, the HCV IRES can initiate translation by an alternative mechanism that does not require known initiation factors. Specifically, the HCV IRES was shown to initiate translation in a reconstituted system consisting only of purified $40 S$ and 605 subunits, elongation factors, and aminoacylated tRNAs at high magnesium concentration. Analyses of assembled complexes supported a mechanism by which preformed 80S ribosomes can assemble directly on the HCV IRES at high cation concentrations. This mechanism is reminiscent of that employed by the divergent IRES elements in the Dicistroviridae, exemplified by the cricket paralysis virus, which mediates initiation of protein synthesis without initiator tRNA.
\end{abstract}

Keywords: translation; IRES; HCV; CrPV; magnesium concentration

\section{INTRODUCTION}

Hepatitis $\mathrm{C}$ virus (HCV) infects over 170 million people worldwide and causes fibrosis of the liver, which can ultimately result in liver cirrhosis, hepatic failure, or hepatocellular carcinoma (Wasley and Alter 2000; Pawlotsky 2004). Like many viruses, HCV has evolved a number of different mechanisms to counter the host anti-viral immune response (Gale and Foy 2005).

One such emerging mechanism may be the divergent mode of translation initiation of the HCV genome. Translational initiation of the HCV polyprotein is mediated by a structural RNA motif, termed the internal ribosome entry site (IRES), which is located within the $5^{\prime}$ noncoding region of the 9.5-kb nucleotide HCV RNA genome (Tsukiyama-Kohara et al. 1992; Wang et al. 1993). HCV IRES-dependent translation is mechanistically different from both cap-dependent initiation and IRES utilization by viruses, such as picornaviruses, in that it is both $5^{\prime}$ endand scanning-independent (Tsukiyama-Kohara et al. 1992; Wang et al. 1993; Pestova et al. 1998). Briefly, cap-dependent

Reprint requests to: Peter Sarnow, Department of Microbiology and Immunology, Stanford University School of Medicine, Fairchild Science Building D309b, 299 Campus Drive, Stanford, CA 94305, USA; e-mail: psarnow@stanford.edu; fax: (650) 498-7147.

Article published online ahead of print. Article and publication date are at http://www.rnajournal.org/cgi/doi/10.1261/rna.2342306. translation of most host mRNAs is initiated by an interaction of the $\mathrm{m}^{7} \mathrm{G}$-cap structure present at the $5^{\prime}$ end of all cellular mRNAs with a large multifactor cap binding protein complex, eIF4F, to recruit the $43 \mathrm{~S}$ complex, which consists of the small ribosomal subunit, 40S, eIF3, eIF1, eIF1a, eIF5, and the ternary complex, eIF2/GTP/MettRNA $_{i}{ }^{\text {Met }}$ (Hershey and Merrick 2000). The 43S complex then scans the mRNA in an ATP-dependent manner until an appropriate AUG codon is encountered. Upon basepairing of the AUG start codon with the anticodon of Met$\mathrm{tRNA}_{\mathrm{i}}{ }^{\mathrm{Met}}$, GTP hydrolysis-dependent release of initiation factors occurs, resulting in $60 \mathrm{~S}$ joining and assembly of $80 \mathrm{~S}$ ribosomes with the initiator Met-tRNA ${ }_{i}{ }^{\text {Met }}$ positioned in the ribosomal P-site (Huang et al. 1997; Hershey and Merrick 2000; Pestova et al. 2000). In contrast, the HCV IRES can recruit $40 \mathrm{~S}$ subunits independently of either a $\mathrm{m}^{7} \mathrm{G}$-cap structure or an ATP, arguing that ATP-dependent scanning is not required and only a minimal set of initiation factors is necessary to assemble $80 \mathrm{~S}$ subunits.

Reconstitution and cell-free translation experiments have provided insights into the sequential steps leading to the formation of HCV IRES-80S complexes. The current model supports a mechanism by which the HCV IRES first forms binary complexes with $40 \mathrm{~S}$ subunits, aided by a higher-order RNA structure termed "domain III" in the IRES. Subsequently, eIF3 and the eIF2/GTP/Met-tRNA ${ }_{i}{ }^{\text {Met }}$ complex are recruited to form $48 \mathrm{~S}$ initiation complexes, 
aided by IRES domains III and IIIb. Finally, after GTP hydrolysis and release of eIF2, the $60 \mathrm{~S}$ subunit joins to assemble the $80 \mathrm{~S}$ ribosome, a step that is mediated by domain II and portions of domain III of the IRES (Pestova et al. 1998; Ji et al. 2004; Otto 2004). This model predicts that the eIF2/GTP/Met-tRNA ${ }_{i}^{\text {Met }}$ complex is required for recognition of the AUG codon in HCV IRES-mediated translation (Otto 2004). However, this model is inconsistent with the finding that HCV IRES-mediated translation was stimulated when the $\alpha$-subunit of eIF2 was phosphorylated by protein kinase PKR (Rivas-Estilla et al. 2002). Phosphorylation of eIF2 $\alpha$ reduces the pool of translationcompetent ternary complexes, leading to overall cessation of translation (Kaufman 1999). In addition, it was noted that the HCV IRES could efficiently initiate translation at non-AUG codons in rabbit reticulocyte lysates (Reynolds et al. 1995), suggesting translational initiation mediated by this IRES may also follow unconventional rules.

In this report, we show that the HCV IRES allows, under certain conditions, initiation factor-independent translation. This mechanism has previously been demonstrated only in the IRES elements located in the genomes of viruses belonging to the Dicistroviridae (Hellen and Sarnow 2001; Pisarev et al. 2005). A prototypical Dicistroviridae IRES is exemplified by the IRES of cricket paralysis virus (CrPV). This IRES forms binary complexes by direct binding of $40 \mathrm{~S}$ subunits and assembles $80 \mathrm{~S}$ ribosomes without the aid of canonical translation factors, starting protein synthesis at a non-AUG codon in the ribosomal A-site (Wilson et al. 2000a; Jan and Sarnow 2002; Jan et al. 2003; Pestova and Hellen 2003). Thus, the HCV IRES may have evolved several mechanisms to initiate translation, possibly to escape anti-viral host responses that inhibit either capdependent or initiation-factor-dependent translation of viral and host mRNAs.

\section{RESULTS}

\section{The HCV IRES displays little sensitivity to edeine, which prevents AUG recognition by scanning eIF2/GTP/Met-tRNA ${ }_{i}^{\text {Met }}$ complexes}

The HCV IRES is known to initiate translation at non-AUG codons (Reynolds et al. 1995), raising the possibility of translational initiation in the absence of ternary eIF2/GTP/Met-tRNA ${ }_{i}^{\text {Met }}$ complexes. To test this possibility, we examined the sensitivity of the HCV IRES activity to the translation initiation inhibitor edeine, which interferes with AUG start-codon recognition by scanning eIF2/GTP/Met-tRNA ${ }_{i}^{\text {Met }}$ com- plexes (Kozak and Shatkin 1978; Odom et al. 1978). Dicistronic mRNAs that contained the IRES elements from encephalomyocarditis virus (EMCV) (Jang et al. 1988), cricket paralysis virus (CrPV) (Wilson et al. 2000a), or HCV (Tsukiyama-Kohara et al. 1992; Wang et al. 1993) in the intercistronic spacer region were incubated in rabbit reticulocyte lysates (RRL) with increasing amounts of edeine. Translational activities were compared by measuring enzymatic activities of products of both the first and second cistrons. As predicted, $5^{\prime}$ cap-dependent translation of the first cistrons of all the dicistronic mRNAs was inhibited, to $20 \%$ and $2 \%$ of the uninhibited activity, respectively, in the presence of $250 \mathrm{nM}$ and $500 \mathrm{nM}$ edeine (Fig. 1A). Second-cistron synthesis mediated by the EMCV IRES was inhibited to a similar extent at these concentrations of edeine, supporting the finding that this IRES requires AUG start-codon recognition by scanning ternary complexes (Kaminski et al. 1994). In contrast, translation initiation mediated by the CrPV IGR IRES remained at $70 \%$ of the uninhibited activity at $250 \mathrm{nM}$ edeine (Wilson et al. 2000a). Edeine inhibits translation elongation at higher concentrations (Szer and Kurylo-Borowska 1970; Carrasco et al. 1974), and, accordingly, CrPV IRES activity was diminished to $40 \%$ of the uninhibited activity at $500 \mathrm{nM}$ edeine (Fig. 1A). Like the CrPV IRES, the HCV IRES displayed relative insensitivity to edeine, suggesting that recognition of the AUG start codon in the IRES may not require a scanning ternary complex of the initiator tRNA it carries.

\section{Edeine-insensitive translation initiation mediated by the HCV IRES occurs with the AUG start codon in the ribosomal $P$ site}

Translation initiation usually starts in the ribosomal P-site, where the AUG start codon is engaged in base-pair interaction

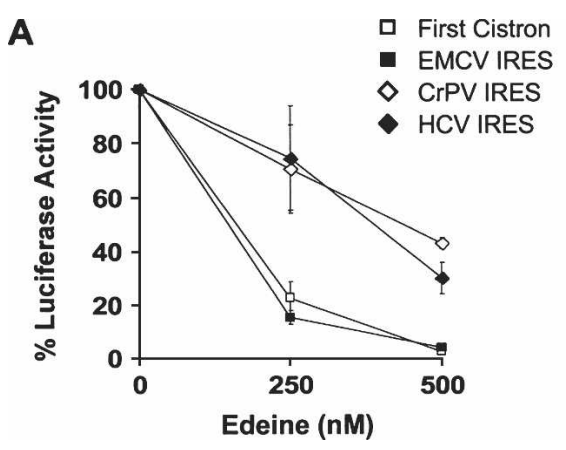

FIGURE 1. Effects of the translation initiation inhibitor edeine on cap-dependent and IRESmediated translation in the RRL. (A) Enzymatic assays. Extracts were programmed with dicistronic RNAs containing either the EMCV IRES, CrPV IRES, or HCV IRES with increasing amounts of edeine. (B) Peptide synthesis. RRL was programmed with monocistronic RNAs, encoding short open reading frames downstream from the CrPV IRES, the wild-type HCV IRES with an AUG start codon, or a mutant HCV IRES with a UAG stop codon. Extracts were incubated with ${ }^{35} \mathrm{~S}$ methionine, and reaction products were separated by electrophoresis on a $16.5 \%$ Tris-tricine gel. An autoradiograph of the gel is shown. 
with the initiator Met-tRNA ${ }_{i}^{\text {Met }}$. To examine the possibility that the HCV IRES initiates edeine-insensitive translation at a codon other than the AUG start codon, we compared the accumulation of wild-type and mutant HCV IRESmediated translation products synthesized in the absence or the presence of edeine in the RRL. As predicted, CrPV IRES-mediated translation produced a peptide of similar size and only slightly reduced abundance in the presence or the absence of edeine (Fig. 1B). Similarly, the HCV IRES directed the synthesis of a peptide of similar size and slightly reduced abundance in the presence and the absence of edeine, indicating that translation initiated at or near the same codon (Fig. 1B). In a control reaction, no detectable peptide was synthesized from a mutated HCV IRES in which the AUG start codon was replaced with a UAG stop codon (Fig. 1B, lanes 5,6).

To determine the site of translation initiation more rigorously, toeprinting analysis was employed. In this technique, an oligodeoxynucleotide primer is annealed to template mRNA followed by extension with reverse transcriptase. Primer extension stops, or toeprints, are the result of inhibition of reverse transcription by either RNA secondary structure or blockage by a ribosome complex. From the size of the arrested cDNA product, the codons in the P- and A-site of the ribosome can be deduced: The arrested cDNA product is usually $15-17 \mathrm{nt}$ from the first nucleotide of the triplet in the ribosomal P site (Hartz et al. 1989; Anthony and Merrick 1992), although changes in ribosomal conformation can also affect this position (Jan and Sarnow 2002; Jan et al. 2003; Pestova and Hellen 2003).

Initiation complexes were formed on EMCV, CrPV, and HCV IRESs in the RRL in the presence of cycloheximide to allow the accumulation of $80 \mathrm{~S}$ initiation complexes on the mRNAs. As shown previously, initiation complex formation on the EMCV IRES produced a toeprint $+16 \mathrm{nt}$ from the A nucleotide of the AUG start codon (Pestova et al. 1996; Fig. 2A, lane 1). Reactions containing increasing amounts of edeine inhibited the appearance of the toeprint on the EMCV IRES, indicating that edeine inhibited initiation complex formation at the AUG codon, presumably by inhibition of ternary complex formation (Fig. 2A, lanes 2-4).

In contrast, toeprints were detected on $\mathrm{CrPV}$ and $\mathrm{HCV}$ IRESs at $250 \mathrm{nM}$ and $500 \mathrm{nM}$ edeine concentrations (Fig. $2 \mathrm{~B}, \mathrm{C}$, lanes 2,3). Initiation complexes formed on the HCV IRES in the presence or the absence of edeine produced the same toeprint at $+15 / 16 \mathrm{nt}$, indicating that the HCV IRES AUG start codon occupied the ribosomal $\mathrm{P}$ site in the presence or the absence of edeine (Fig. 2B, lanes 1-3). This result is consistent with the assays displayed in Figure 1, which showed that HCV IRES-mediated translation was quite refractory to edeine and initiated translation at or near the AUG start codon in the presence or the absence of edeine. Unlike the HCV and EMCV IRESs, initiation complexes formed on the CrPV IRES-produced toeprints at both $+13 / 14$ and $+19 / 20$ from the C codon of the CCU

\section{A EMCV IRES}

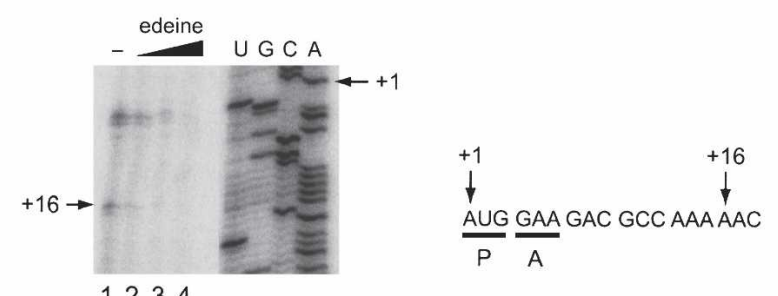

B HCV IRES

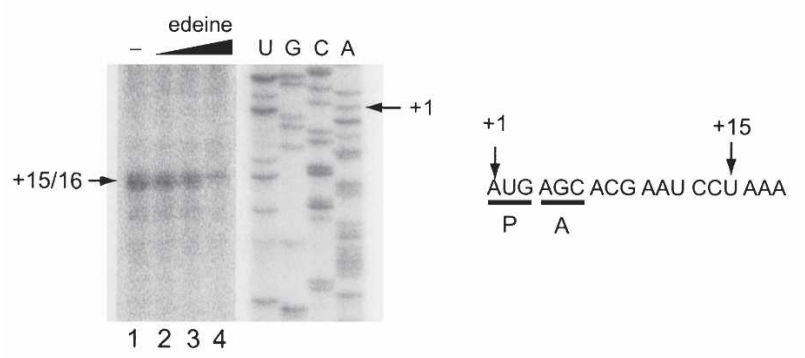

C CrPVIRES

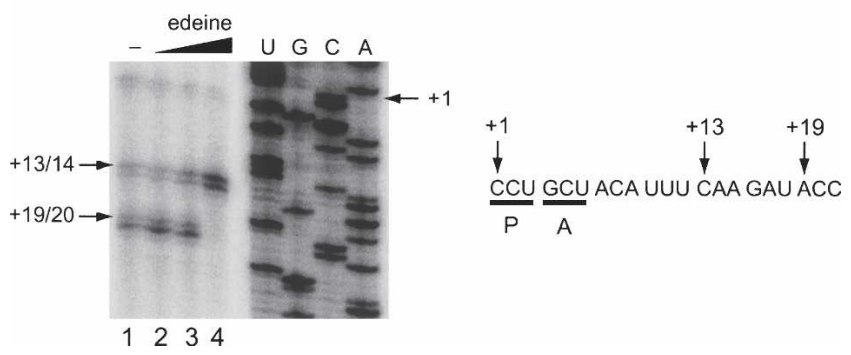

FIGURE 2. Toeprinting analysis of translation initiation complexes. Initiation complexes were allowed to form on EMCV IRES $(A)$, HCV IRES $(B)$, or CrPV IRES $(C)$ in mock treated (lane 1 ) or treated with $250 \mathrm{nM}$ (lane 2), $500 \mathrm{nM}$ (lane 3) or $1 \mu \mathrm{M}$ edeine (lane 4) in the RRL. Extracts were supplemented with cycloheximide to freeze initiating $80 \mathrm{~S}$ complexes. Bound initiation complexes were analyzed by primer extension analysis using AMV RT in the presence of $\left[\alpha-{ }^{32} \mathrm{P}\right]$ dATP and arrested cDNA products were visualized on $5 \% 6 \mathrm{M}$ ureacontaining polyacrylamide gels. PhosphorImages of the gels are shown.

triplet in the ribosomal $\mathrm{P}$-site in the presence and the absence of edeine (Fig. 2C, lanes 1-3). This discrepancy is due to an unusual mechanism of CrPV IRES-mediated ribosome assembly. Specifically, the CrPV IRES can translocate two cycles of elongation in the presence of cycloheximide (Wilson et al. 2000a; Jan et al. 2003; Pestova and Hellen 2003). However, at the highest edeine concentration $(1 \mu \mathrm{M})$, only a predominant toeprint at $+13 \mathrm{nt}$ was observed. The absence of the $+19 / 20$ toeprint is likely to reflect the known inhibition of ribosome elongation at high concentrations of edeine (Szer and Kurylo-Borowska 1970; Jan et al. 2003). The HCV and CrPV IRES elements share the ability to form binary 40S-IRES complexes that position the start-site codon, AUG in HCV IRES and CCU in the CrPV IRES, in the ribosomal P-site. Therefore, initiation of protein synthesis on the HCV IRES by formation of binary 
40S-mRNA complexes is refractory to edeine concentrations that normally inhibit base-pairing of initiator tRNA with the AUG start codon by scanning 40S-ternary eIF2/GTP/Met-tRNA ${ }_{i}^{\text {Met }}$ complexes.

\section{HCV IRES facilitates translation initiation in the absence of translation initiation factors}

To test the independence of HCV IRES function from canonical initiation factors in another way, we monitored translation in an in vitro reconstituted system containing only ribosomes, tRNAs, and translation elongation factors. As a positive control, we compared the HCV IRES with the CrPV IRES, which has been shown to initiate translation in the absence of initiation factors in such an in vitro reconstituted system (Jan et al. 2003; Pestova and Hellen 2003). IRES-containing mRNAs were incubated with purified saltwashed ribosomes, purified yeast elongation factors eEF1a and eEF2, and bulk aminoacylated tRNAs. As predicted, the CrPV IRES mediated the synthesis of peptides while the EMCV IRES, which requires canonical initiation factors for initiation, was unable to do so (Fig. 3A,B). The wild-type HCV IRES failed to direct the synthesis of a peptide in the presence of $2.5 \mathrm{mM}$ $\mathrm{MgCl}_{2}$ (Fig. 3A, lane 7), which is normally used in translation-competent extracts. Remarkably, both the CrPV (Fig. 3B, lane 2) and the HCV IRES (Fig. 3A, lane 5) were able to direct the synthesis of peptides in the reconstituted system in the presence of $5 \mathrm{mM} \mathrm{MgCl}_{2}$. This IRES activity was significant, because HCV IRES-mediated translation in the reconstituted system at this magnesium concentration yielded at least $5 \%$ of translation products as in the RRL (data not shown). As expected, translation mediated by all three IRES elements remained sensitive to cycloheximide, which inhibits translation elongation (Fig. 3A). Translation initiation in translation-competent extracts is usually inhibited at magnesium concentrations $>2.5 \mathrm{mM}$ (Shenvi et al. 2005). Given the results reported here, however, high magnesium concentration seems to primarily inhibit factor-dependent translation initiation.

To examine effects of the start codon on HCV IRESmediated peptide synthesis in the high-magnesium reconstituted system, we tested the activities of HCV IRES initiation codon mutants. All HCV IRES initiation mutant constructs, including the IRES containing a UAG stop

C are shown.
B
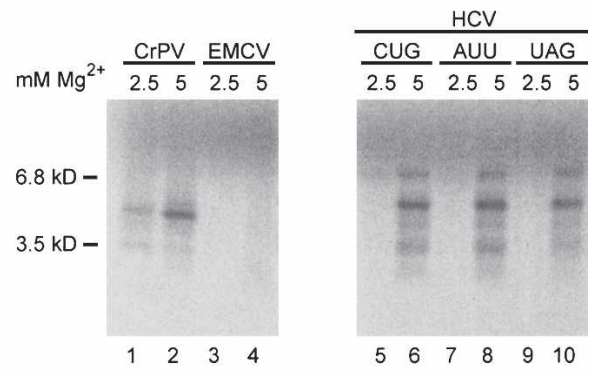

$\begin{array}{llllll}5 & 6 & 7 & 8 & 9 & 10\end{array}$

FIGURE 3. IRES-mediated translation in a reconstituted translation system. (A) Magnesium dependence of wild-type IRESs. In vitro transcribed RNAs containing CrPV IRES (lanes 1,2), $60 \mathrm{~S}$, elongation factors $1 \mathrm{~A}$ and 2 and bulk aminoacylated tRNAs. Cycloheximide was added as EMCV IRES, HCV IRES, or mutant HCV IRESs were treporter RNAs containing CrPV IRES, described above Mutant HCV IRESs contained CUG, AUU, and UAG start-codon mutations as indicated. $(C)$ Cation dependence of HCV IRES-mediated translation in the reconstituted system. All reactions contained $2.5 \mathrm{mM} \mathrm{Mg}^{2+}$ and supplemented cations as indicated. Peptides were resolved on $16.5 \%$ Tris-Tricine SDS-polyacrylamide gels, and PhosphorImages of the gels

codon in place of the AUG initiation codon, were able to direct synthesis of peptides of similar size in the reconstituted system at $5 \mathrm{mM} \mathrm{MgCl} 2$ (Fig. 3B). As explained above, it cannot be tested whether the UAG stop-codon mutant is active in the RRL, because translation reactions are inhibited in the RRL at $5 \mathrm{mM}$ cation concentrations. To determine whether HCV IRES-mediated translation in the reconstituted system required specific cations, we tested effects of monovalent $\mathrm{K}^{+}$cations and divalent $\mathrm{Mg}^{2+}, \mathrm{Ca}^{2+}$, and $\mathrm{Zn}^{2+}$ cations, as well as the charged peptide analog spermidine, in the reconstituted system. Only the divalent $\mathrm{Mg}^{2+}$ and $\mathrm{Ca}^{2+}$ cations were able to promote detectable HCV IRES-mediated translation initiation in the reconstituted system (Fig. 3C), whereas the EMCV IRES was unable to synthesize peptides under any conditions tested (data not shown). Therefore, the HCV IRES can direct peptide synthesis in the absence of initiation factors at elevated divalent $\mathrm{Mg}^{2+}$ or $\mathrm{Ca}^{2+}$ concentrations. However, it should be kept in mind that initiator tRNA molecules were present in the reconstituted translation reactions and these molecules could play a role in translation initiation if they interacted with the ribosome in an eIF2-independent manner. 


\section{HCV IRES binds $80 \mathrm{~S}$ ribosomes at high magnesium concentrations}

The dependence on increased magnesium cations of factorindependent HCV IRES translation could be due to a number of reasons. One possibility is that magnesium could affect HCV IRES RNA structure. While this possibility cannot be ruled out at present, chemical and enzymatic structural probing analyses have shown that the HCV IRES structure does not change significantly at a concentration range from 2.5 to $10 \mathrm{mM} \mathrm{MgCl}_{2}$ (Kieft et al. 1999). On the other hand, increased magnesium could affect ribosomal subunit structure, resulting in altered association rates of the HCV IRES with ribosomal $40 \mathrm{~S}$ subunits or $80 \mathrm{~S}$ ribosomes. Indeed, it has been shown that nucleotides in ribosomal RNAs are more accessible to chemical modification at $2.5 \mathrm{mM} \mathrm{MgCl}_{2}$ than at $10 \mathrm{mM} \mathrm{MgCl}_{2}$, suggesting that the ribosome is more rigid at higher magnesium concentration (Shenvi et al. 2005).

To determine if increased concentrations of $\mathrm{Mg}^{2+}$ or $\mathrm{Ca}^{2+}$ affected the stoichiometry of free subunits and $80 \mathrm{~S}$ ribosomes, purified $40 \mathrm{~S}$ and $60 \mathrm{~S}$ subunits were mixed in the presence of $2.5 \mathrm{mM}$ or $5 \mathrm{mM} \mathrm{Mg}^{2+}$ as well as in a combination of $2.5 \mathrm{mM} \mathrm{Mg}^{2+}$ plus $2.5 \mathrm{mM} \mathrm{Ca}^{2+}$ and subsequently separated in sucrose gradients. The amount of 40S, 60S, and $80 \mathrm{~S}$ in each fraction was determined by Northern analysis using hybridization probes that detect $18 \mathrm{~S}$ rRNA (Fig. 4A) and $28 \mathrm{~S}$ rRNA (Fig. 4B). At both $\mathrm{Mg}^{2+}$ concentrations,
A
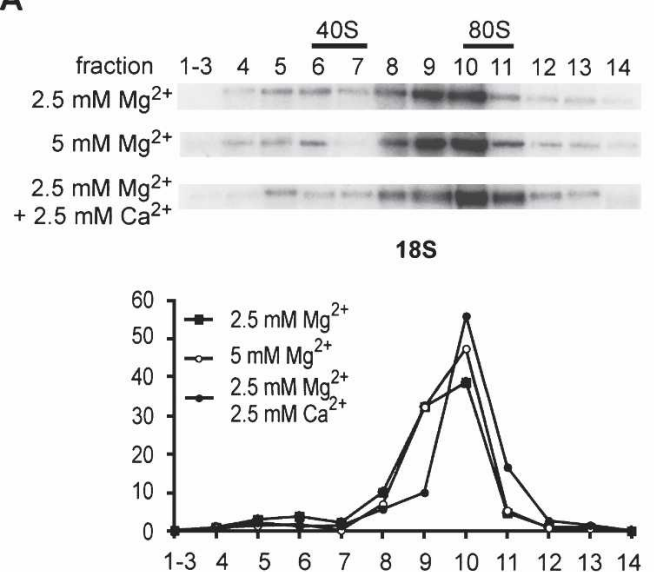

C

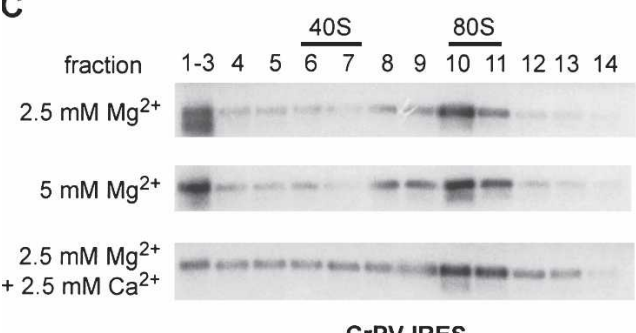

CrPV IRES

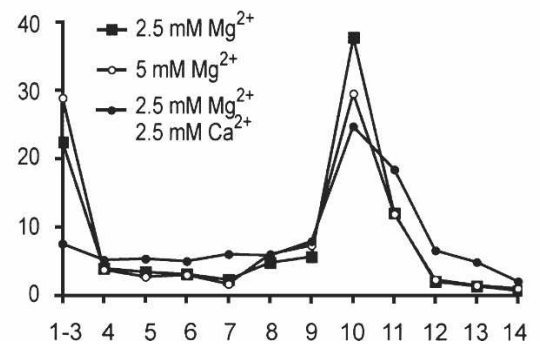

B

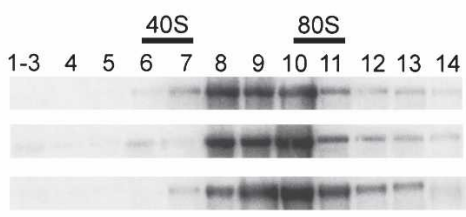

28S

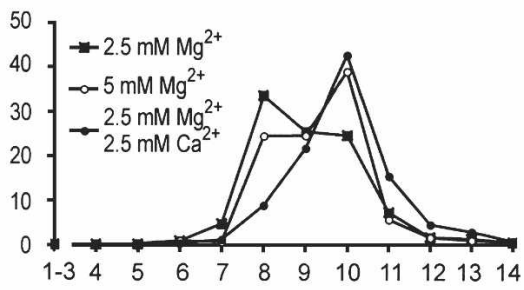

D
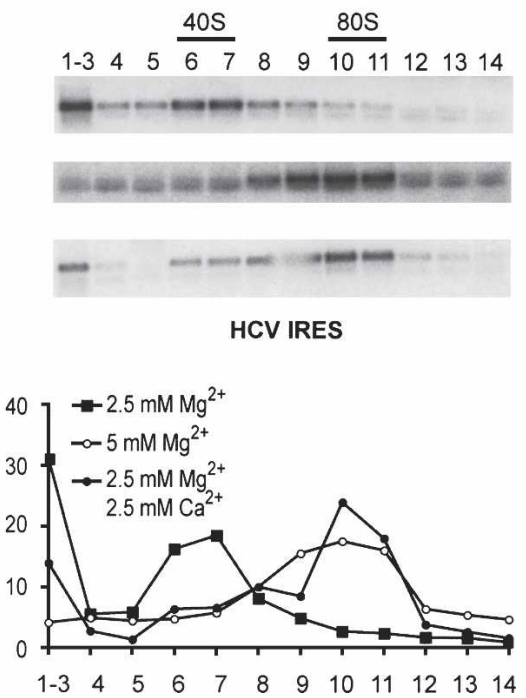

FIGURE 4. Sucrose gradient analysis of ribosome assembly and IRES-80S complex formation. 40S and 60S purified HeLa ribosomal subunits were incubated at $2.5 \mathrm{mM} \mathrm{Mg}^{2+}, 5 \mathrm{mM} \mathrm{Mg}^{2+}$, or a combination of $2.5 \mathrm{mM} \mathrm{Mg}^{2+}$ and $2.5 \mathrm{mM} \mathrm{Ca}^{2+}$ without added RNA to test the abundance of $40 \mathrm{~S}, 60 \mathrm{~S}$, and $80 \mathrm{~S}$ species by monitoring $18 \mathrm{~S}$ rRNAs $(A)$ and $28 \mathrm{~S}$ rRNAs $(B)$. The gradient positions of CrPV IRES RNA $(C)$ and HCV IRES RNA $(D)$, when these RNAs were incubated with ribosomal subunits, are shown. Reactions were sedimented on $10 \%-30 \%$ sucrose gradients with the same buffer conditions. Gradients were fractionated, RNA was isolated, and Northern blot analysis was performed to monitor 18S rRNA (A), 28S rRNA $(B)$, CrPV IRES $(C)$, or HCV IRES RNA $(D)$. The graphs below the blots represent quantitations of the Northern blot data. 
similar amounts of $80 \mathrm{~S}$ ribosomes were formed, with only a small amount of free $40 \mathrm{~S}$ subunits remaining (Fig. 4A,B). The $2.5 \mathrm{mM} \mathrm{Mg}^{2+}$ plus $2.5 \mathrm{mM} \mathrm{Ca}^{2+}$ reaction yielded a slightly more homogenous population of $80 \mathrm{~S}$ subunits. As shown in Figure 4B, the free 60S peak observable in the presence of $\mathrm{Mg}^{2+}$ was not observable in the presence of both $\mathrm{Mg}^{2+}$ and $\mathrm{Ca}^{2+}$. Therefore, cations can significantly affect ribosomal subunit association.

We next tested the binding of ribosomes to the CrPV and HCV IRES elements at various cation concentrations. The CrPV IRES bound to $80 \mathrm{~S}$ ribosomes at all concentrations of divalent cations tested (Fig. 4C). In contrast, the sedimentation of the HCV IRES was dependent on the cation concentration in the reaction. At $2.5 \mathrm{mM} \mathrm{MgCl}_{2}$, the IRES sedimented both as unbound RNA at the top of the gradient and cosedimented with 40S subunits (Fig. 4D). Interestingly, at the higher cation concentrations, the majority of the HCV IRES cosedimented with 80 S ribosomes (Fig. 4D). In contrast, the EMCV IRES did not bind to 40S or $80 \mathrm{~S}$ ribosomes under any of the conditions tested (data not shown). Although the majority of the HCV IRES cosediments with $80 \mathrm{~S}$ ribosomes at high cation concentrations, factor-independent translation by the HCV IRES was moderately inhibited in reactions containing $2.5 \mathrm{mM}$ $\mathrm{Mg}^{2+}$ and $\mathrm{Ca}^{2+}$ compared to that with $5 \mathrm{mM} \mathrm{Mg}^{2+}$ (Fig. $3 \mathrm{C})$. It is possible that the addition of $\mathrm{Ca}^{2+}$ enhances the formation of 80S-HCV IRES complexes but inhibits translation at a post-initiation step. In summary, these results indicate that the increased cation dependence for factorindependent HCV IRES translation correlated with a higher propensity for the HCV IRES to bind to 80 S ribosomes at high cation concentration.

\section{DISCUSSION}

It has been well established that HCV IRES-mediated translation starts with the formation of a binary 40S-IRES complex, followed by recruitment of eIF3 and the eIF2/ GTP/Met-tRNA ${ }_{i}{ }^{\text {Met }}$ complex to form a $48 \mathrm{~S}$ complex. After GTP hydrolysis and release of eIF2, the $60 \mathrm{~S}$ subunit joins to assemble 80S-IRES complex (Pestova et al. 1998; Ji et al. 2004; Otto 2004). However, previous reports have revealed that the HCV IRES can initiate translation using non-AUG initiation codons (Reynolds et al. 1995) and under conditions that limit the overall pool of the ternary complex (Rivas-Estilla et al. 2002). Using the RRL and purified translation factors, we show here that the HCV IRES can initiate translation by an alternative mechanism that is similar to one employed by the CrPV IRES (Sasaki and Nakashima 2000; Wilson et al. 2000a; Jan et al. 2003). Several lines of evidence support this conclusion. First, the HCV IRES-mediated translation in the RRL is refractory to the translation inhibitor, edeine, which inhibits AUG recognition by the scanning 40S-ternary complex (Kozak and Shatkin 1978). Second, the HCV IRES can direct translation in a reconstituted system that is devoid of initiation factors and only contains purified 40S and 60S subunits, elongation factors, and aminoacylated tRNAs at high magnesium concentration. Third, the HCV IRES can assemble $80 \mathrm{~S}$ ribosomes from purified $40 \mathrm{~S}$ and $60 \mathrm{~S}$ subunits. Together, these properties suggest that the HCV IRES does not require eIF3 or the ternary complex for $80 \mathrm{~S}$ assembly for translation initiation under certain conditions.

Edeine binds to the ribosome between the P- and the E-sites, and inhibits tRNA binding in the P-site by preventing codon-anticodon interactions (Dinos et al. 2004). The CrPV IRES can bypass the inhibitory effects of edeine because the IRES occupies the ribosomal P-site as a tRNA mimic, allowing subsequent protein synthesis to commence from the ribosomal A site (Wilson et al. 2000a; Spahn et al. 2004). Using toeprinting analyses in the RRL, stalled initiation complexes were located on the HCV IRES with the AUG codon occupying the ribosomal P-site in the presence and the absence of edeine. However, it is not known whether an initiator Met-tRNA molecule occupies the ribosomal P site in the presence of edeine in HCV IRESribosome complexes. More likely, edeine inhibits scanning ribosomal $40 \mathrm{~S}$ ternary complexes and the $\mathrm{CrPV}$ and $\mathrm{HCV}$ IRESs can bypass the inhibitory effects by direct recruitment of $40 \mathrm{~S}$ subunits to the initiation codon.

Like the CrPV IRES, the HCV IRES can also direct translation from non-AUG start site codons. Mutated HCV IRESs containing mutant initiation codons could direct translation in the reconstituted system at high cation concentrations. Moreover, the peptides synthesized from mutant IRES-containing mRNAs displayed the same sizes as those translated from wild-type IRES-harboring mRNAs, suggesting that translation occurred at or near the same codons. Currently, the first aminoacylated tRNA that is used for HCV IRES-mediated translation in the reconstituted system is not known. However, because a mutant HCV IRES containing a UAG initiation codon mediated protein synthesis in the reconstituted system at $5 \mathrm{mM}$ $\mathrm{MgCl}_{2}$, a noncognate aminoacylated tRNA must have been used for initiation using the UAG triplet as the start codon under these conditions. It has been shown that elevated levels of $\mathrm{Mg}^{2+}$ increase the affinity of the ribosome for tRNA, allowing for noncognate decoding of poly (U) mRNA by leucyl-tRNA (Gavrilova and Rutkevitch 1980; Schilling-Bartetzko et al. 1992). It is thus possible that the increased $\mathrm{Mg}^{2+}$ concentration allows for initiation with a noncognate tRNA at the UAG initiation codon from ribosomes that assembled on the IRES in a factor-independent manner. Alternatively, translation initiation may occur with a Met-tRNA ${ }_{i}^{\text {Met }}$ from the P-site of the ribosome as the initiator tRNA is present in all conditions tested in this study, or translation initiation may occur with a cognate elongator tRNA from the A-site of the ribosome, a mechanism similar to that of the CrPV IRES. 
An interesting difference between the CrPV and HCV IRESs is that the HCV IRES can only initiate translation in the reconstituted system at the higher $5 \mathrm{mM}$ cation concentration whereas the CrPV IRES can initiate translation at lower cation concentrations. Our results indicate that the HCV IRES has a greater affinity for the $80 \mathrm{~S}$ ribosomes at $5 \mathrm{mM} \mathrm{Mg}^{2+}$ than at $2.5 \mathrm{mM} \mathrm{Mg}^{2+}$. It is possible that the ribosome has an altered conformation at higher magnesium concentration (Shenvi et al. 2005), which can more readily form a complex with the HCV IRES.

Further insights into the mechanisms by which the HCV and CrPV IRES elements interact with the ribosome can be deduced from cryo EM studies. The CrPV IRES forms a complex secondary structure consisting of three overlapping pseudoknot structures (Jan and Sarnow 2002). Cryo EM analysis of CrPV IRES-40S complexes has revealed that the IRES occupies the ribosomal mRNA cleft that is normally occupied by tRNAs (Spahn et al. 2004). Moreover, cryo EM images of HCV IRES-40S complexes have shown that, like the CrPV IRES, part of the HCV IRES protrudes into the mRNA cleft, possibly mimicking tRNA interactions with the ribosome (Spahn et al. 2001). Although the RNA structures between the HCV IRES and the CrPV IRES are distinct, both IRESs are susceptible to RNAse P cleavage (Lyons and Robertson 2003), an RNAse that specifically recognizes tRNA structures and cleaves precursor tRNAs to yield mature tRNA (Schurer et al. 2001). Finally, cryo EM studies have shown that both IRESs induce similar ribosomal conformational changes in IRESribosome complexes (Spahn et al. 2001, 2004). For example, "latch" interactions form between the head and the body of the ribosome near the entrance of the mRNA channel. It has been proposed that this latch interaction helps to guide the mRNA into the mRNA channel in IRESribosome complexes, clearly an important step in translation initiation (Spahn et al. 2001, 2004).

Overall, these findings argue that the HCV IRES, like certain divergent IRES elements from insect viruses, can mediate protein synthesis aided only by elongation factors and tRNA molecules and without significant amounts of canonical eukaryotic translation initiation factors at $5 \mathrm{mM}$ $\mathrm{Mg}^{2+}$. While the efficiency with which the HCV IRES mediates translation initiation is enhanced in the presence of initiation factors, the IRES can also use the less efficient initiation mechanism, which does not depend on initiation factors. These findings suggest that the HCV IRES could use this mechanism to initiate translation even during phosphorylation of eIF $2 \alpha$ and the subsequently diminished pool of ternary initiation complexes, induced by stress- or virus-induced kinases of the innate arm of the cellular immune response. The HCV IRES could also continue to mediate translation when intracellular $\mathrm{Mg}^{2+}$ and $\mathrm{Ca}^{2+}$ concentrations are high. These experiments outline a novel pathway of HCV IRES-mediated translation and also show that increased cation concentrations may lead to the accumulation of ribosomal subunits with distinct biological properties.

\section{MATERIALS AND METHODS}

\section{DNA constructs}

A DNA fragment containing the HCV IRES between two luciferase cistrons, described by Lukavsky et al. (2000), was inserted into pGem4 using the EcoRI and XbaI restriction sites. The dicistronic luciferase plasmids containing the CrPV IGR and EMCV IRESs have been described in Wilson et al. (2000b). Monocistronic luciferase constructs containing the EMCV and CrPV IRESs have been described in Wilson et al. (2000a) as have monocistronic luciferase constructs containing the HCV IRES in Lukavsky et al. (2000). Initiation codon mutants were constructed in the monocistronic HCV IRES luciferase construct using the QuikChange site-directed mutagenesis kit (Stratagene).

\section{In vitro transcription and translation}

Monocistronic and dicistronic luciferase constructs that contain the IRESs were digested with HindIII and transcribed using the SP6 RiboMax in vitro transcription kit (Promega) as described in Otto et al. (2002). Uncapped RNAs were translated in RRL (Promega) in the presence of $154 \mathrm{mM}$ potassium acetate. In edeine inhibition studies, the RRL was preincubated with the indicated concentrations of edeine for $10 \mathrm{~min}$ on ice before addition of RNA. Reactions were incubated for at $30^{\circ} \mathrm{C}$ for $25 \mathrm{~min}$.

\section{Reconstitution assays}

For the peptide synthesis experiments, bulk tRNAs were aminoacylated using a mixture of amino acids including ${ }^{35} \mathrm{~S}$-methionine (Jan et al. 2003). Reactions contained $30 \mathrm{nM}$ dicistronic RNA, $130 \mathrm{nM}$ $40 \mathrm{~S}$ subunits, $330 \mathrm{nM} 60 \mathrm{~S}$ subunits, $1 \mathrm{mM}$ ATP, $1 \mathrm{mM}$ GTP, $80 \mathrm{ng} / \mu \mathrm{l} \mathrm{eEF1A}, 100 \mathrm{ng} / \mu \mathrm{l} \mathrm{eEF} 2$, and $380 \mathrm{ng} / \mu \mathrm{l}$ aa-tRNAs. $80 \mathrm{~S}$ ribosomes were assembled for $5 \mathrm{~min}$ at $37^{\circ} \mathrm{C}$. After addition of elongation factors and aminoacylated-tRNAs, reactions were incubated at $37^{\circ} \mathrm{C}$ for $30 \mathrm{~min}$. Peptide synthesis reactions were separated on $16.5 \%$ Tris-Tricine gels at $50 \mathrm{~V}$ for $12 \mathrm{~h}$.

\section{$40 S$ and 605 subunit purification}

Ribosomal subunits were purified from HeLa cell pellets (National Center for Research Resources) as previously described in Lukavsky et al. (2000). HeLa cells were lysed in a Triton X-100 lysis buffer (15 mM Tris- $\mathrm{HCl}$ at $\mathrm{pH} 7.5,300 \mathrm{mM} \mathrm{NaCl}, 6 \mathrm{mM} \mathrm{MgCl}_{2}, 1 \%$ Triton X-100, $1 \mathrm{mg} / \mathrm{mL}$ Heparin). Lysates were spun briefly to remove debris and then layered on a $30 \%(\mathrm{w} / \mathrm{w}) \quad 0.5 \mathrm{M} \mathrm{KCl}$ sucrose cushion to pellet ribosomes. Polysomes were resuspended in Buffer B (20 mM Tris- $\mathrm{HCl}$ at pH 7.5, $6 \mathrm{mM} \mathrm{Mg}$ acetate, $150 \mathrm{mM}$ $\mathrm{KCl}, 6.8 \%$ sucrose $[\mathrm{w} / \mathrm{w}], 1 \mathrm{mM}$ DTT), treated with puromycin (Blobel and Sabatini 1971), and $\mathrm{KCl}$ was added to a final concentration of $0.5 \mathrm{M}$. The dissociated ribosomes were separated on a $10 \%-30 \%(\mathrm{w} / \mathrm{w})$ sucrose gradient. The $40 \mathrm{~S}$ and $60 \mathrm{~S}$ peaks were detected at $260 \mathrm{~nm}$, pooled, concentrated using Centricon 50 spin concentrators (Amicon) in Buffer C $(20 \mathrm{mM}$ Tris- $\mathrm{HCl}$ at $\mathrm{pH}$ 7.5, $0.2 \mathrm{mM}$ EDTA, $10 \mathrm{mM} \mathrm{KCl}, 1 \mathrm{mM} \mathrm{MgCl}_{2}, 6.8 \%$ sucrose [w/w]) 
and stored at $-80^{\circ} \mathrm{C}$. Western blot analysis showed that subunit preparations were devoid of detectable levels of eIF2 and eIF3, except a trace amount of the p40 subunit of eIF3 (data not shown). $18 \mathrm{~S}$ and $28 \mathrm{~S}$ rRNA in subunit preparations were examined to judge the purity of $40 \mathrm{~S}$ and $60 \mathrm{~S}$. Concentrations of $40 \mathrm{~S}$ and $60 \mathrm{~S}$ subunits were determined by spectrophotometry, using the conversions $1 \mathrm{OD}_{260 \mathrm{~nm}}=50 \mathrm{nM}$ for $40 \mathrm{~S}$ and $1 \mathrm{OD}_{260 \mathrm{~nm}}=25 \mathrm{nM}$ for $60 \mathrm{~S}$ subunits.

\section{Assembly and analysis of ribosomal complexes}

Toeprinting analysis of ribosomal complexes using purified subunits was performed as described in Wilson et al. (2000a). Briefly, $0.5 \mu \mathrm{g}$ of monocistronic HCV, EMCV, and CrPV IRES RNAs were first annealed with primer PrEJ69 in a buffer containing $40 \mathrm{mM}$ Tris ( $\mathrm{pH}$ 7.5), $0.2 \mathrm{mM}$ EDTA, by slow cooling from $65^{\circ} \mathrm{C}$ to $35^{\circ} \mathrm{C}$. Annealed RNAs were incubated in Buffer $\mathrm{E}$ containing either $40 \mathrm{~S}(40 \mathrm{nM})$ or $60 \mathrm{~S}(40 \mathrm{nM})$, or $40 \mathrm{~S}$ and $60 \mathrm{~S}$ subunits (both $40 \mathrm{nM}$ ). Ribosomal complexes were analyzed by primer extension analysis as described in Pestova et al. (1996) using AMV reverse transcriptase in the presence of $\alpha-{ }^{32} \mathrm{P}$ dATP (3000 Ci/mmol; Amersham).

\section{Aminoacylation of bulk bovine liver tRNA}

Bulk liver tRNAs and in vitro synthesized tRNAs were aminoacylated using a tRNA synthetase extract from HeLa cells (Pestova and Hellen 2001). The extent of aminoacylation was monitored by ${ }^{35} \mathrm{~S}$-methionine and ${ }^{3} \mathrm{H}$-alanine incorporation and by gel filtration analysis. Aminoacylation of tRNAs was greater than $75 \%$.

\section{Sucrose gradients}

High salt-washed, purified HeLa cell $40 \mathrm{~S}$ and $60 \mathrm{~S}$ ribosomal subunits were incubated in the same buffer conditions as the reconstituted translation system, with either 2.5 or $5 \mathrm{mM} \mathrm{MgCl}_{2}$, or at a combination of $2.5 \mathrm{mM} \mathrm{MgCl}$ and $2.5 \mathrm{CaCl}_{2}$, then sedimented on a $10 \%-30 \%$ sucrose gradient in the same buffer. The gradients were then fractionated, and ribosomal RNA (rRNA) was collected from each fraction, separated on a denaturing $0.8 \%$ agarose gel, transferred, and UV-cross-linked to a Zeta-probe membrane. Ribosomal RNAs were visualized by methylene blue staining and 28 rRNA was probed with an end-radiolabeled oligonucleotide probe to the $3^{\prime}$ end of $28 \mathrm{~S}$ rRNA. HCV IRES RNA was preincubated with ribosomes at both $2.5 \mathrm{mM}$ and $5 \mathrm{mM}$ $\mathrm{MgCl}_{2}$; the reactions were then sedimented on $10 \%-30 \%$ sucrose gradients. The gradients were fractionated and then subjected to Northern blot analysis to determine the presence of the HCV IRES in the gradient fractions.

\section{ACKNOWLEDGMENTS}

We are grateful to Karla Kirkegaard and Kara Norman for critical reading of the manuscript. We are especially thankful to Kara Norman for assisting in production of some of the figures. We thank Terri Goss Kinzy and Karen Browning for the generous gift of purified elongation factors. The work was supported by NIH grants T32 GM07276 (A.M.L.) and R01 AI47365 (P.S.), and by Damon Runyon Cancer Research Foundation grant DRG-1630 (E.J.).

Received December 22, 2005; accepted February 1, 2006.

\section{REFERENCES}

Anthony, D.D. and Merrick, W.C. 1992. Analysis of 40 S and 80S complexes with mRNA as measured by sucrose density gradients and primer extension inhibition. J. Biol. Chem. 267: 1554-1562.

Blobel, G. and Sabatini, D. 1971. Dissociation of mammalian polyribosomes into subunits by puromycin. Proc. Natl. Acad. Sci. 68: 390-394.

Carrasco, L., Battaner, E., and Vazquez, D. 1974. The elongation steps in protein synthesis by eukaryotic ribosomes: Effect of antibiotics. Methods Enzymol. 30: 282-289.

Dinos, G., Wilson, D.N., Teraoka, Y., Szaflarski, W., Fucini, P., Kalpaxis, D., and Nierhaus, K.H. 2004. Dissecting the ribosomal inhibition mechanisms of edeine and pactamycin: The universally conserved residues G693 and C795 regulate P-site RNA binding. Mol. Cell 13: 113-124.

Gale Jr., M. and Foy, E.M. 2005. Evasion of intracellular host defence by hepatitis C virus. Nature 436: 939-945.

Gavrilova, L.P. and Rutkevitch, N.M. 1980. Ribosomal synthesis of polyleucine on polyuridylic acid as a template: Contribution of the elongation factors. FEBS Lett. 120: 135-140.

Hartz, D., McPheeters, D.S., and Gold, L. 1989. Selection of the initiator tRNA by Escherichia coli initiation factors. Genes \& Dev. 3: 1899-1912.

Hellen, C.U. and Sarnow, P. 2001. Internal ribosome entry sites in eukaryotic mRNA molecules. Genes \& Dev. 15: 1593-1612.

Hershey, J.W.B. and Merrick, W.C. 2000. The pathway and mechanism of initiation of protein synthesis. In Translational control of gene expression (eds. N. Sonenberg et al.), pp. 33-88. Cold Spring Harbor Laboratory Press, Cold Spring Harbor, New York.

Huang, H.K., Yoon, H., Hannig, E.M., and Donahue, T.F. 1997. GTP hydrolysis controls stringent selection of the AUG start codon during translation initiation in Saccharomyces cerevisiae. Genes \& Dev. 11: 2396-2413.

Jan, E. and Sarnow, P. 2002. Factorless ribosome assembly on the internal ribosome entry site of cricket paralysis virus. J. Mol. Biol. 324: 889-902.

Jan, E., Kinzy, T.G., and Sarnow, P. 2003. Divergent tRNA-like element supports initiation, elongation, and termination of protein biosynthesis. Proc. Natl. Acad. Sci. 100: 15410-15415.

Jang, S.K., Krausslich, H.G., Nicklin, M.J., Duke, G.M., Palmenberg, A.C., and Wimmer, E. 1988. A segment of the 5' nontranslated region of encephalomyocarditis virus RNA directs internal entry of ribosomes during in vitro translation. J. Virol. 62: 2636-2643.

Ji, H., Fraser, C.S., Yu, Y., Leary, J., and Doudna, J.A. 2004. Coordinated assembly of human translation initiation complexes by the hepatitis $\mathrm{C}$ virus internal ribosome entry site RNA. Proc. Natl. Acad. Sci. 101: 16990-16995.

Kaminski, A., Belsham, G.J., and Jackson, R.J. 1994. Translation of encephalomyocarditis virus RNA: Parameters influencing the selection of the internal initiation site. EMBO J. 13: 1673-1681.

Kaufman, R.J. 1999. Stress signaling from the lumen of the endoplasmic reticulum: Coordination of gene transcriptional and translational controls. Genes \& Dev. 13: 1211-1233.

Kieft, J.S., Zhou, K., Jubin, R., Murray, M.G., Lau, J.Y., and Doudna, J.A. 1999. The hepatitis C virus internal ribosome entry site adopts an ion-dependent tertiary fold. J. Mol. Biol. 292: 513-529.

Kozak, M. and Shatkin, A. 1978. Migration of 40S ribosomal subunits on mRNA in the presence of edeine. J. Biol. Chem. 253: 65686577.

Lukavsky, P.J., Otto, G.A., Lancaster, A.M., Sarnow, P., and Puglisi, J.D. 2000. Structures of two RNA domains essential for hepatitis C virus internal ribosome entry site function. Nat. Struct. Biol. 7: $1105-1110$.

Lyons, A.J. and Robertson, H.D. 2003. Detection of tRNA-like structure through RNase $\mathrm{P}$ cleavage of viral internal ribosome entry site RNAs near the AUG start triplet. J. Biol. Chem. 278: 26844-26850. 
Odom, O., Kramer, G., Henderson, A., Pinphanichakarn, P., and Hardesty, B. 1978. GTP hydrolysis during methionyl-tRNAf binding to $40 \mathrm{~S}$ ribosomal subunits and the site of edeine inhibition. J. Biol. Chem. 253: 1807-1816.

Otto, G.A. 2004. The pathway of hepatitis C virus internal ribosome entry site mediated translation initiation. In Microbiology and immunology pp. 187. Stanford University, Stanford, CA.

Otto, G.A., Lukavsky, P.J., Lancaster, A.M., Sarnow, P., and Puglisi, J.D. 2002. Ribosomal proteins mediate the hepatitis C virus IRES-HeLa 40S interaction. RNA 8: 913-923.

Pawlotsky, J.M. 2004. Pathophysiology of hepatitis C virus infection and related liver disease. Trends Microbiol. 12: 96-102.

Pestova, T.V. and Hellen, C.U. 2001. Preparation and activity of synthetic unmodified mammalian tRNAi(Met) in initiation of translation in vitro. RNA 7: 1496-1505.

- 2003. Translation elongation after assembly of ribosomes on the Cricket paralysis virus internal ribosomal entry site without initiation factors or initiator tRNA. Genes \& Dev. 17: 181-186.

Pestova, T.V., Hellen, C.U., and Shatsky, I.N. 1996. Canonical eukaryotic initiation factors determine initiation of translation by internal ribosomal entry. Mol. Cell. Biol. 16: 6859-6869.

Pestova, T., Shatsky, I., Fletcher, S., Jackson, R., and Hellen, C. 1998. A prokaryotic-like mode of cytoplasmic eukaryotic ribosome binding to the initiation codon during internal translation initiation of hepatitis $\mathrm{C}$ and classical swine fever virus RNAs. Genes \& Dev. 12: 67-83.

Pestova, T.V., Lomakin, I.B., Lee, J.H., Choi, S.K., Dever, T.E., and Hellen, C.U. 2000. The joining of ribosomal subunits in eukaryotes requires eIF5B. Nature 403: 332-335.

Pisarev, A.V., Shirokikh, N.E., and Hellen, C.U. 2005. Translation initiation by factor-independent binding of eukaryotic ribosomes to internal ribosomal entry sites. C.R. Biol. 328: 589-605.

Reynolds, J., Kaminski, A., Kettinen, H., Grace, K., Clarke, B., Carroll, A., Rowlands, D., and Jackson, R. 1995. Unique features of internal initiation of hepatitis $\mathrm{C}$ virus RNA translation. EMBO J. 14: 6010-6020.

Rivas-Estilla, A.M., Svitkin, Y., Lopez Lastra, M., Hatzoglou, M., Sherker, A., and Koromilas, A.E. 2002. PKR-dependent mechanisms of gene expression from a subgenomic hepatitis $C$ virus clone. J. Virol. 76: 10637-10653.
Sasaki, J. and Nakashima, N. 2000. Methionine-independent initiation of translation in the capsid protein of an insect RNA virus. Proc. Natl. Acad. Sci. 97: 1325-1327.

Schilling-Bartetzko, S., Franceschi, F., Sternbach, H., and Nierhaus, K.H. 1992. Apparent association constants of tRNAs for the ribosomal A, P, and E sites. J. Biol. Chem. 267: 4693-4702.

Schurer, H., Schiffer, S., Marchfelder, A., and Morl, M. 2001. This is the end: Processing, editing and repair at the tRNA 3 '-terminus. Biol. Chem. 382: 1147-1156.

Shenvi, C.L., Dong, K.C., Friedman, E.M., Hanson, J.A., and Cate, J.H. 2005. Accessibility of $18 \mathrm{~S}$ rRNA in human 40 S subunits and $80 \mathrm{~S}$ ribosomes at physiological magnesium ion concentrations: Implications for the study of ribosome dynamics. RNA 11: $1898-1908$

Spahn, C.M., Kieft, J.S., Grassucci, R.A., Penczek, P.A., Zhou, K., Doudna, J.A., and Frank, J. 2001. Hepatitis C virus IRES RNAinduced changes in the conformation of the 40s ribosomal subunit. Science 291: 1959-1962.

Spahn, C.M., Jan, E., Mulder, A., Grassucci, R.A., Sarnow, P., and Frank, J. 2004. Cryo-EM visualization of a viral internal ribosome entry site bound to human ribosomes: The IRES functions as an RNA-based translation factor. Cell 118: 465-475.

Szer, W. and Kurylo-Borowska, Z. 1970. Effect of edeine on aminoacyltRNA binding to ribosomes and its relationship to ribosomal binding sites. Biochim. Biophys. Acta 224: 477-486.

Tsukiyama-Kohara, K., Iizuka, N., Kohara, M., and Nomoto, A. 1992. Internal ribosome entry site within hepatitis C virus RNA. J. Virol. 66: $1476-1483$.

Wang, C., Sarnow, P., and Siddiqui, A. 1993. Translation of human hepatitis C virus RNA in cultured cells is mediated by an internal ribosome-binding mechanism. J. Virol. 67: 3338-3344.

Wasley, A. and Alter, M.J. 2000. Epidemiology of hepatitis C: Geographic differences and temporal trends. Semin. Liver Dis. 20: $1-16$.

Wilson, J.E., Pestova, T.V., Hellen, C.U., and Sarnow, P. 2000a. Initiation of protein synthesis from the A site of the ribosome. Cell 102: 511-520.

Wilson, J.E., Powell, M.J., Hoover, S.E., and Sarnow, P. 2000b. Naturally occurring dicistronic cricket paralysis virus RNA is regulated by two internal ribosome entry sites. Mol. Cell. Biol. 20: $4990-4999$. 

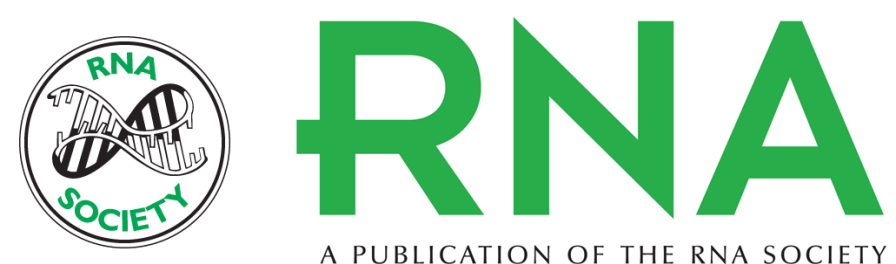

A PUBLICATION OF THE RNA SOCIETY

\section{Initiation factor-independent translation mediated by the hepatitis C virus internal ribosome entry site}

Alissa M. Lancaster, Eric Jan and Peter Sarnow

RNA 2006 12: 894-902

References This article cites 41 articles, 24 of which can be accessed free at:

http://rnajournal.cshlp.org/content/12/5/894.full.html\#ref-list-1

\section{License}

Email Alerting Receive free email alerts when new articles cite this article - sign up in the box at the Service top right corner of the article or click here. 